\title{
COAT Platelets Under Alarm
}

\author{
Thomas Thiele $^{1}$ Stefan Handtke ${ }^{1}$ \\ ${ }^{1}$ Abteilung Transfusionsmedizin, Institut für Immunologie und \\ Transfusionsmedizin, Universitätsmedizin Greifswald, Greifswald, \\ Germany
}

Thromb Haemost 2021;121:1267.

Epinephrineps (adrenaline) is a hormone synthesized by the adrenal gland medulla and by neurons. It is released following physical activity, mental stress, or other conditions associated with sympathoadrenal activation. ${ }^{1}$ Platelets exhibit $\alpha 2 \mathrm{~A}$ adrenergic receptors making them susceptible to systemic epinephrine release. In this context, epinephrine can influence platelet reactivity under systemic stress.

Epinephrine has a rather indirect mode of action by amplifying the response to other agonists. ${ }^{2}$ In this issue of Thrombosis and Haemostasis, Aliotta et $\mathrm{al}^{3}$ investigated the additional impact of epinephrine on procoagulant collagen and thrombin coated (COAT) platelets. COAT platelets are formed after co-stimulation of protease-activated receptors and glycoprotein VI, e.g., with thrombin and convulxin, respectively. COAT platelet formation is associated with phosphatidylserine (PS) exposure and a sustained cytosolic $\mathrm{Ca}^{2+}$ increase and affects a higher proportion of large platelets. $^{4}$

The authors confirm that epinephrine stimulation alone does not affect free cytosolic $\mathrm{Ca}^{2+}$ and elegantly show that it dose dependently reduces free cytosolic $\mathrm{Ca}^{2+}$ of thrombin + convulxin stimulated platelets. This decreases the proportion of PS-positive COAT platelets and increases the proportion of PAC-1-binding aggregatory platelets. Thus, very high doses of 1,000 $\mu \mathrm{M}$ epinephrine switch the platelet response from a procoagulant phenotype toward aggregation.

Albeit such high epinephrine concentrations appear less likely to occur in vivo, Aliotta and colleagues discuss that platelets respond to a 15- to 55-fold lower epinephrine concentration in vivo. Extrapolating their data, such a switch could appear at doses of $6 \mu \mathrm{M}$, coming near to systemic
Address for correspondence Thomas Thiele, MD, Institut für Immunologie und Transfusionsmedizin, Abteilung Transfusionsmedizin, Sauerbruchstrasse, Greifswald 17487, Germany (e-mail: thomas.thiele@med.uni-greifswald.de).

concentrations achieved after epinephrine injection. Further, it is unknown which concentrations of epinephrine appear in the microenvironment around vascular injuries, where platelets begin to act. This deserves future investigations. Meanwhile, it is a rational hypothesis that epinephrine modulates procoagulant COAT and pro-aggregatory platelet formation when the organism is alarmed or when patients receive high doses of catecholamines.

Funding

S.H. is funded by Deutsche Forschungsgemeinschaft (DFG, German Research Foundation; Projektnummer 374031971TRR 240.

Conflict of interest

None declared.

\section{References}

1 Anfossi G, Trovati M. Role of catecholamines in platelet function: pathophysiological and clinical significance. Eur J Clin Invest 1996;26(05):353-370

2 Lanza F, Beretz A, Stierlé A, Hanau D, Kubina M, Cazenave JP. Epinephrine potentiates human platelet activation but is not an aggregating agent. Am J Physiol 1988;255(6, Pt 2):H1276-H1288

3 Aliotta A, Bertaggia Calderara D, Zermatten MG, Alberio L. Highdose epinephrine enhances platelet aggregation at the expense of procoagulant activity. Thromb Haemost 2021;121(10): 1337-1344

4 Handtke S, Wesche J, Palankar R, Greinacher A, Thiele T. Function of large and small platelets differs, depending on extracellular calcium availability and type of inductor. Thromb Haemost 2020; 120(07):1075-1086

\section{received}

July 23, 2021

accepted

July 26, 2021

published online

August 24, 2021 (c) 2021. Thieme. All rights reserved. Georg Thieme Verlag KG,

Rüdigerstraße 14,

70469 Stuttgart, Germany
DOI https://doi.org/

10.1055/s-0041-1735190. ISSN 0340-6245. 